\title{
The Otis Group Intelligence Scale Applied to the Elementary-School Graduating Classes of Oakland, California
}

\section{Virgil E. Dickson \& John K. Norton}

To cite this article: Virgil E. Dickson \& John K. Norton (1921) The Otis Group Intelligence Scale Applied to the Elementary-School Graduating Classes of Oakland, California, The Journal of Educational Research, 3:2, 106-115, DOI: 10.1080/00220671.1921.10879137

To link to this article: http://dx.doi.org/10.1080/00220671.1921.10879137

Published online: 15 Dec 2014.

Submit your article to this journal ¿

View related articles 5 


\section{THE OTIS GROUP INTELLIGENCE SCALE APPLIED TO THE ELEMENTARY-SCHOOL GRADUATING CLASSES OF OAKLAND, CALIFORNIA}

Virgil E. Dickson AND John K. Norton

Bureau of Research and Guidance, Public Schools, Oakland, California

Both individual and group intelligence tests have been extensively used in the public schools of Oakland, California for a number of years. Their value as administrative tools is well established. They have contributed to a better understanding of many school problems such as retardation, elimination, and proper curriculum modification; and they have resulted in administrative adjustments leading to greater efficiency.

This article presents certain data from tests of 1,043 day elementary-school pupils who completed the eighth grade in Oakland, January, 1920. This includes all those graduated at that time except a small number who were absent from school the day the tests were given. The Otis Group Intelligence Scale, as abbreviated for use in Oakland, was employed in making the tests. The abbreviation omits tests $1,6,9$, and 10 . It includes tests 2,3 , $4,5,7$, and 8 without modification as to directions for giving, timing, or scoring, except that tests 4 and 5 are given double value in the final score in order that they may contribute a greater amount to the final test result. The highest possible score with the abbreviated test is 175 .

In order that the six-test scores obtained at Oakland may be compared with the scores arising from the use of the complete test, Dr. Arthur S. Otis, the deviser of the test, has furnished Table I. By its use a ten-test score may be transmuted into a six-test score.

The tens and hundreds digits of the six-test score are printed in italics in the line across the top; the units digits of the six-test score are printed in italics in the column at the left. To find the ten-test score corresponding to a known six-test score find in the body of the table the number under the tens digit (or tens and hundreds digits combined) and opposite the units digit. For ex- 
TABLE I. A TABLE FOR TRANSMUTING TEN-TEST SCORES INTO SIXTEST SCORES, OMITTING TESTS $1,6,9$, AND 10 . (OTIS GROUP INTELLIGENCE SCALE)

\begin{tabular}{|c|c|c|c|c|c|c|c|c|c|c|c|c|c|}
\hline \multirow{2}{*}{$\begin{array}{l}\text { Units } \\
\text { Digits of } \\
\text { Six-test } \\
\text { Score }\end{array}$} & \multicolumn{13}{|c|}{ Tens and Hundreds Digits of Six-test Score } \\
\hline & 0 & 1 & 2 & 3 & 4 & 5 & 6 & 7 & 8 & 9 & 10 & 11 & 12 \\
\hline 1 & 10 & 26 & 42 & 58 & 74 & 91 & 107 & 123 & 140 & 154 & 167 & 181 & 195 \\
\hline 2 & 11 & 27 & 43 & 60 & 76 & 92 & 109 & 125 & 141 & 155 & 168 & 182 & 196 \\
\hline 3 & 13 & 29 & 45 & 61 & 78 & 94 & 110 & 127 & 143 & 157 & 170 & 184 & 198 \\
\hline 4 & 14 & 30 & 46 & 63 & 79 & 96 & 112 & 128 & 144 & 158 & 171 & 185 & 199 \\
\hline 5 & 16 & 32 & 48 & 64 & 81 & 97 & 114 & 130 & 146 & 160 & 173 & 187 & 201 \\
\hline 6 & 18 & 34 & 50 & 66 & 82 & 99 & 115 & 132 & 147 & 161 & 174 & 188 & 202 \\
\hline 7 & 19 & 35 & 51 & 68 & 84 & 100 & 117 & 133 & 148 & 162 & 175 & 189 & 203 \\
\hline 8 & 21 & 37 & 53 & 69 & 86 & 102 & 118 & 135 & 150 & 163 & 177 & 191 & 205 \\
\hline 9 & 22 & 38 & 55 & 71 & 87 & 104 & 120 & 136 & 151 & 164 & 178 & 192 & 206 \\
\hline 0 & 24 & 40 & 56 & 73 & 89 & 105 & 122 & 138 & 153 & 166 & 180 & 194 & 208 \\
\hline
\end{tabular}

ample the following six-test scores correspond to the indicated ten-test scores:

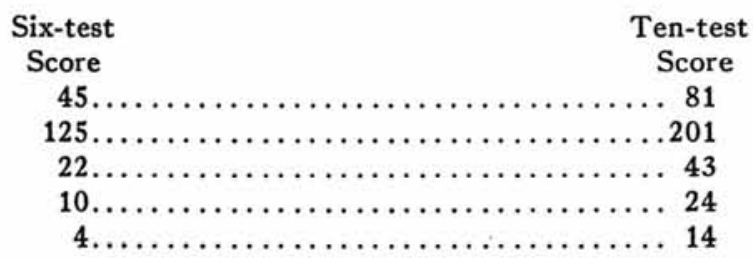

The tests were made in the school month just preceding the date of graduation. At the time of making the test, the following supplementary data were obtained for each child: name, age in years and months, date and hour of the test, and teachers' ratings in school work. Teachers were asked to rate pupils for general quality of school work on a scale of seven points as follows: (1) very superior; (2) superior; (3) slightly above average; (4) average; (5) slightly below average; (6) inferior; (7) very inferior.

When several teachers rated a child in school work, the average of their ratings was taken. If this resulted in a fraction, the child was assigned the rating of the nearest whole number. When the fraction was an even half, the rating was given the value of the 


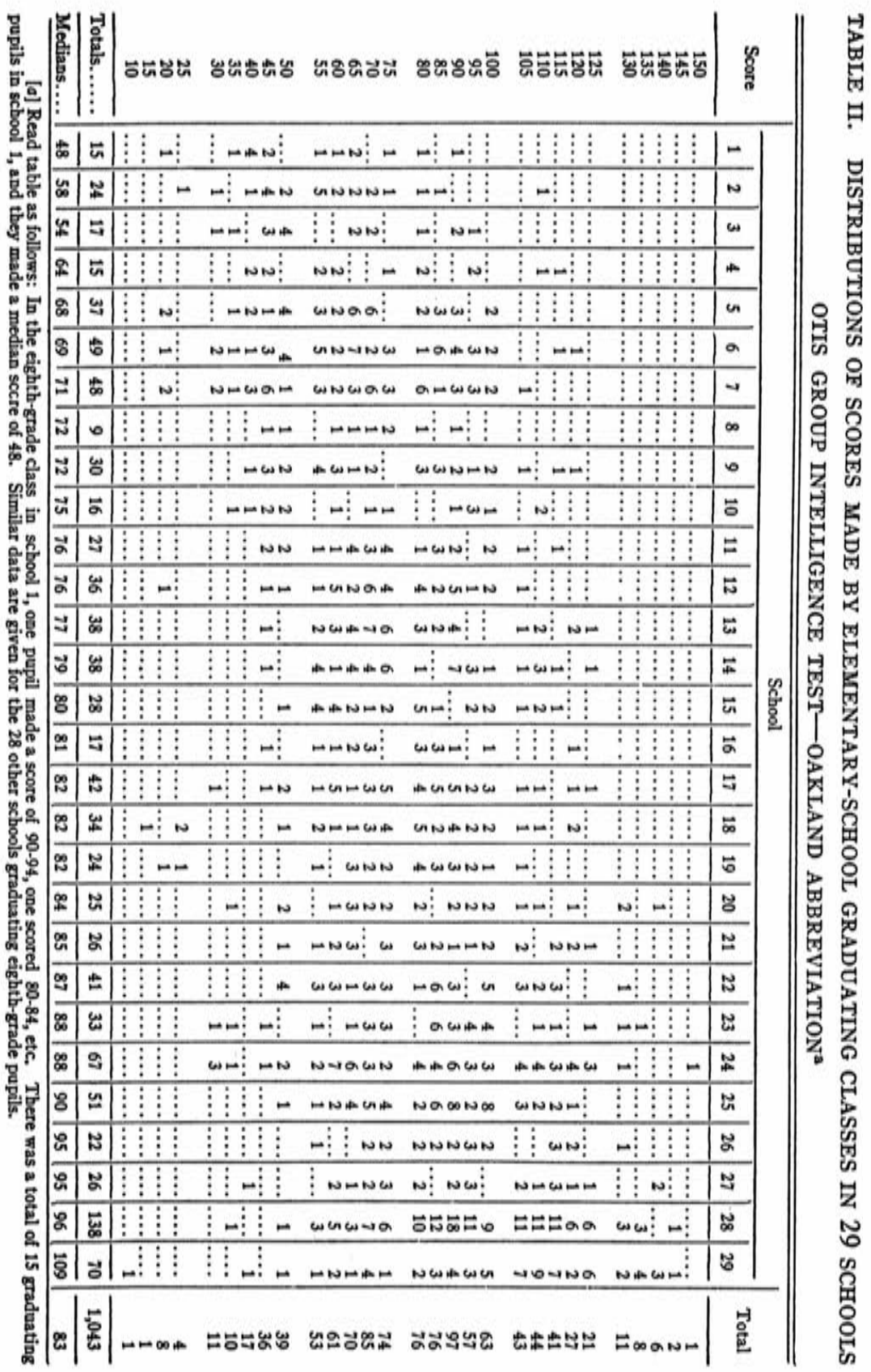


whole number farthest removed from the rating of 4 . That is 3.5 was tabulated as 3, 4.5 as 5, etc. Succeeding paragraphs present and briefly point out the significance of the data resulting from the test and the collection of the supplementary information.

Table II gives distributions of scores made by graduating classes of the 29 schools of the city. A wide variation in capacity as measured by the test is shown both by different high eighth grades and by different individuals in the same class. Individual scores range from 14 to 152 points and class medians from 48 to 109. The significance of these differences can be better understood by consulting Figure 1. This compares the ranges of the middle 50 percents for four different groups: (1) the elementary graduating classes of the two schools making the highest medians; (2) a high ninth-grade class of average ability tested at about the same time as the elementary graduating classes; (3) the elementary graduating classes in the three schools making the lowest median scores; (4) two high sixth-grade classes recently tested.

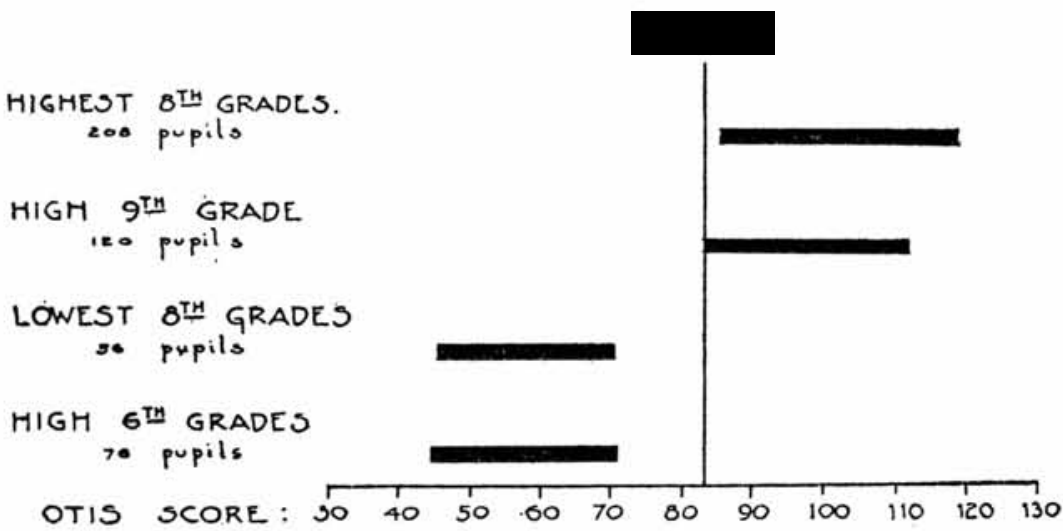

FIGURE 1. RANGE OF OTIS TEST SCORES MIDDLE FIFTY PERCENT.

It is evident that ability as measured by the test in the eighthgrade classes in some of the schools is equal to that in a freshman class which has survived a year in high school and is just ready to begin sophomore work; while the ability found in other eighth grades is no better than that of groups of children who have not yet completed the sixth grade. If the test means anything in 
terms of ability to do school work, certainly the actual accomplishments of the different classes graduating in January, 1920 must have varied widely.

These data show how important it is to know the character of the human material with which a teacher is working, before a judgment is passed on the results obtained. A poor teacher working with an eighth-grade class with the capacity of high-school freshmen might very easily get better results than a good teacher working with an eighth-grade class with a capacity not above that of the ordinary sixth grade. Teachers are too often judged wholly on a basis of results, whereas the important factor, the learning capacity of children, is given but little thought.

The necessity of making modifications in the curriculum to meet the varying abilities of different classes of the same grade designation, and of different individuals in the same class, is another point emphasized by the data of Table II.

Modifications certainly must be made either in the character of the curriculum or in the time given by different classes of the same grade to any particular block of subject-matter if proper consideration is to be given to the wide differences in capacity which the test reveals in grades of the same designation.

Table III gives the data concerning the relationship between test scores and ratings in school work. There is a positive correlation of 0.538 (Pearson formula). Even were the test perfect in its measurement of mental capacity, we should not expect a complete correlation between test scores and school work. Such factors as the following all tend to destroy correlation:

1. All children do not put forth equal effort; some of good native ability may do poor work due to lack of application, and some of poor native ability may compensate by unusual effort.

2. Repetition of grades sometimes brings up the school work of those of poor native ability.

3. Desirable or undesirable personal characteristics may unduly influence a teacher in her estimate of a child's work.

4. Different classes of the same grade vary so widely in general ability that the same score may represent high or low ability, according to the class in which it occurs.

5. In a small number of cases the test score is probably unduly influenced by extreme nervousness, illness, or other interfering factors. 
TABLE III. OTIS SCALE SCORE AND RATING IN SCHOOL WORK[a]

\begin{tabular}{|c|c|c|c|c|c|c|c|c|}
\hline \multirow{2}{*}{ Score } & \multicolumn{7}{|c|}{ School Work Rating } & \multirow{2}{*}{ Totals } \\
\hline & 7 & 6 & 5 & 4 & 3 & 2 & 1 & \\
\hline 150 & $\cdots$ & $\cdots$ & $\cdots$ & $\ldots \ldots$ & $\mid \ldots \ldots$ & 1 & $\ldots \ldots$ & 1 \\
\hline 145 & $\ldots \ldots$ & $\ldots \ldots$ & $\ldots \ldots$ & $\ldots \ldots$ & $\ldots \ldots$ & 1 & 1 & 2 \\
\hline 140 & $\ldots \ldots$ & $\ldots \ldots$ & $\ldots \ldots$ & $\ldots \ldots$ & 2 & $\ldots \ldots$ & 4 & 6 \\
\hline 135 & $\ldots \ldots$ & $\ldots \ldots$ & $\ldots \ldots$ & $\ldots \ldots$ & 1 & 3 & 4 & 8 \\
\hline 130 & $\ldots \ldots$ & $\ldots \ldots$ & $\ldots \ldots$ & 4 & 1 & 3 & 2 & 10 \\
\hline 125 & $\ldots \ldots$ & $\ldots \ldots$ & 1 & 4 & 9 & 6 & 1 & 21 \\
\hline 120 & $\ldots \ldots$ & 1 & $\ldots \ldots$ & 5 & 10 & 10 & 1 & 27 \\
\hline 115 & $\ldots \ldots$ & $\ldots \ldots$ & 3 & 7 & 21 & 8 & 2 & 41 \\
\hline 110 & $\ldots \ldots$ & $\ldots \ldots$ & $\ldots \ldots$ & 10 & 14 & 16 & 4 & 44 \\
\hline 105 & $\ldots \ldots$ & 1 & 3 & 11 & 21 & 7 & $\ldots \ldots$ & 43 \\
\hline 100 & $\ldots \ldots$ & 1 & 12 & 25 & 17 & 8 & $\ldots \ldots$ & 63 \\
\hline 95 & $\ldots \ldots$ & 1 & 6 & 29 & 12 & 7 & 2 & 57 \\
\hline 90 & $\ldots \ldots$ & 1 & 7 & 46 & 26 & 13 & 2 & 95 \\
\hline 85 & ....... & 1 & 9 & 34 & 23 & 9 & $\ldots \ldots$ & 76 \\
\hline 80 & $\ldots \ldots$ & 1 & 13 & 32 & 15 & 12 & $\ldots \ldots$ & 73 \\
\hline 75 & 1 & 7 & 11 & 31 & 10 & 7 & 2 & 69 \\
\hline 70 & 1 & 7 & 23 & 36 & 11 & 4 & $\ldots \ldots$ & 82 \\
\hline 65 & 4 & 7 & 23 & 20 & 11 & 3 & 2 & 70 \\
\hline 60 & 2 & 8 & 12 & 28 & 11 & $\ldots .$. & $\ldots \ldots$ & 61 \\
\hline 55 & 1 & 8 & 21 & 11 & 6 & 1 & $\ldots \ldots$ & 48 \\
\hline 50 & 4 & 10 & 10 & 10 & 4 & 1 & $\ldots \ldots$ & 39 \\
\hline 45 & 2 & 9 & 6 & 5 & 9 & $\ldots .$. & $\ldots \ldots$ & 31 \\
\hline 40 & 1 & 4 & 6 & 3 & $\ldots \ldots$ & $\ldots \ldots$ & $\ldots \ldots$ & 14 \\
\hline 35 & $\ldots \ldots$ & 6 & 1 & 2 & ........ & $\ldots \ldots$ & $\ldots \ldots$ & 9 \\
\hline 30 & 2 & 3 & 4 & $\ldots \ldots$ & 1 & $\ldots \ldots$ & $\ldots \ldots$ & 10 \\
\hline 25 & $\ldots \ldots$ & 2 & 2 & $\ldots \ldots$ & ....... & $\ldots \ldots$ & $\ldots \ldots$ & 4 \\
\hline 20 & 1 & 1 & 3 & 2 & $\ldots \ldots$ & $\ldots \ldots$ & $\ldots \ldots$ & 7 \\
\hline $15-19$ & $\ldots \ldots$ & $\ldots \ldots$ & 1 & $\ldots \ldots$ & $\ldots \ldots$ & $\ldots \ldots$ & $\ldots \ldots$ & 1 \\
\hline $10-14$ & ....... & 1 & ....... & ....... & $\ldots \ldots$ & $\ldots \ldots$ & ....... & 1 \\
\hline Totals ........ & 19 & 80 & 177 & 355 & 235 & 120 & 27 & $1013[b]$ \\
\hline Median Scores & 54 & 57 & 70 & 85 & 93 & 102 & 119 & 84 \\
\hline
\end{tabular}

$r=0.538$.

[a] Read table as follows: Of the pupils rated 7 (very inferior) in school work one scored between 75 and 79; one scored between 70 and 74; etc. Of those rated 6 (inferior), one scored between 120 and 124; one between 105 and 109 ; etc.

[b] Thirty pupils included in Table II are omitted as they had not been in the Oakland schools a suffcient time to make it possible for teachers to rate them in school work. 
6. The degree of homogeneity of the group tested is an important consideration in estimating the value of a correlation figure. The group dealt with here, high eight-grade children, is probably as homogeneous as is found in any grade.

But in spite of all these factors that tend to destroy correlation, the test score gives a good indication of the character of school work a child will do. Table IV, worked out on the percentage basis, is more conclusive on this point than the correlation figure. Of the fifty children composing the 5 percent making the highest test scores, none were rated 7 in school work, none were rated 6,2 percent were rated 5 or below average, and the rest were rated average or above. School ratings for the other percentage groups are also given. These ratings show conclusively that the test score is a valuable indication of the type of work children do.

The data contained in Table $\mathrm{V}$ show the relation between chronological age and test scores for the 1,043 children. The younger children in the grade generally made the higher scores in the test. Those who were twelve years old made a median score of 110 , and there was a marked drop in the median of each higher age group. In short, the bright children who learn rapidly and earn extra promotions made high scores on the test, while the over-age plodders, in spite of the extra years they have spent in school, show their mental inferiority by making low scores. Of the 44 children who were seventeen years of age, 82 percent made scores below the median for the whole group, while of those twelve years of age, 82 percent were above the median.

TABLE IV. OTIS SCALE SCORE AND RATING IN WORK IN PERCENTS[a]

\begin{tabular}{|c|c|c|c|c|c|c|c|c|}
\hline \multirow{2}{*}{$\begin{array}{c}\text { Percentile } \\
\text { (Otis Scale) }\end{array}$} & \multicolumn{7}{|c|}{ School Work Rating ${ }^{[b]}$} & \multirow{2}{*}{ Totals } \\
\hline & 7 & 6 & 5 & 4 & 3 & 2 & 1 & \\
\hline 95 to 100 & 0 & 0 & 2.0 & 18 & 26 & 30 & 24 & 100 \\
\hline 85 to 95 & 0 & 0.9 & 1.9 & 18.8 & 43.5 & 30.6 & 3.9 & 99.6 \\
\hline 65 to 85 & 0 & 1.4 & 12.3 & 40.3 & 28.0 & 15.2 & 2.4 & 99.6 \\
\hline 35 to 65 & 0.6 & 3.2 & 14.1 & 46.0 & 23.0 & 11.5 & 1.3 & 99.1 \\
\hline 15 to 35 & 2.9 & 11.3 & 28.5 & 36.4 & 15.7 & 3.4 & 0.9 & 99.1 \\
\hline 5 to 15 & 6.9 & 22.7 & 29.7 & 21.7 & 17.8 & 0.9 & 0 & 99.7 \\
\hline 0 to 5 & 7.8 & 37.2 & 35.2 & 17.6 & 1.9 & 0 & 0 & 99.7 \\
\hline
\end{tabular}

[a] Read table as follows: of the highest 5 percent of the group according to Otis test scores, none were rated 7 in school work, none were rated 6, 2 percent were rated 5 , etc.

[b] " 1 ", in school work is very superior,

" 2 "' in school work is superior.

" 3 " in school work is slightly above average, etc., see above. 
TABLE V. OTIS GROUP INTELLIGENCE SCALE SCORE AND CHRONOLOGICAL AGE. 1,043 GRADUATING ELEMENTARYSCHOOL CHILDREN[a]

\begin{tabular}{|c|c|c|c|c|c|c|c|c|}
\hline \multirow{2}{*}{ Score } & \multicolumn{7}{|c|}{ Ages } & \multirow{2}{*}{ Totals } \\
\hline & $11^{[b]}$ & 12 & 13 & 14 & 15 & 16 & 17 & \\
\hline $150-159$ & $\ldots \ldots$ & 1 & $\cdots$ & $\cdots$ & $\cdots$ & $\cdots$ & $\cdots$ & 1 \\
\hline $140-149$ & ....... & 1 & 4 & 2 & 1 & $\ldots . .$. & $\ldots \ldots$ & 8 \\
\hline $130-139$ & 1 & 1 & 7 & 5 & 3 & 2 & ...... & 19 \\
\hline $120-129$ & $\ldots \ldots$ & 1 & 13 & 22 & 9 & 3 & ...... & 48 \\
\hline $110-119$ & ....... & 4 & 24 & 36 & 15 & 5 & 1 & 85 \\
\hline $100-109$ & & 1 & 19 & 44 & 34 & 8 & $\ldots .$. & 106 \\
\hline 90-99 & $\ldots \ldots$ & 3 & 23 & 54 & 56 & 14 & 4 & 154 \\
\hline $80-89$ & $\ldots \ldots$ & 2 & 30 & 52 & 52 & 12 & 4 & 152 \\
\hline $70-79$ & ...... & 1 & 15 & 53 & 57 & 28 & 5 & 159 \\
\hline $60-69$ & $\ldots \ldots$ & 1 & 7 & 42 & 46 & 27 & 8 & 131 \\
\hline $50-59$ & $\ldots \ldots$ & ....... & 4 & 24 & 31 & 24 & 9 & 92 \\
\hline $40-49$ & $\ldots \ldots$ & $\ldots .$. & $\ldots \ldots$ & 11 & 24 & 13 & 5 & 53 \\
\hline $30-39$ & ....... & $\ldots .$. & $\ldots \ldots$ & 2 & 8 & 7 & 4 & 21 \\
\hline $20-29$ & & ...... & $\ldots \ldots$ & 4 & 2 & 4 & 2 & 12 \\
\hline $10-19$ & $\cdots \cdots$ & $\cdots$ & $\cdots \cdots$ & $\cdots \cdots$ & $\ldots \ldots$ & $\ldots \ldots$ & 2 & 2 \\
\hline Totals.......... & 1 & 16 & 146 & 351 & 338 & 147 & 44 & 1,043 \\
\hline Median Score.. & $134^{[c]}$ & 110 & 94 & 84 & 80 & 70 & 60 & 83 \\
\hline
\end{tabular}

$r=-0.44$.

[a] Read table as follows. One child aged eleven scored between 130 and 139; one aged twelve scored between 150 and 159; one aged fifteen scored between 140 and 149 ; etc.

$[b]$ Age eleven includes those from ten years and six months to eleven years and five months; age twelve from eleven years and six months to twelve years and five months.

[c] Score of one case.

Figure 2 compares the range of the middle 50 percent of each age group. It would be hard to present data more conclusive than these regarding the value of the test as a measure of the capacity for accomplishment in school work as it is now constituted.

The administrative uses to which intelligence-test results may be put are many. They may be used in studying pupils in groups; that is, the human material in one school can be compared with that in another. The classes of the same grade and of different grades within a school can also be accurately measured as to general capacity. The group intelligence test has already been used 


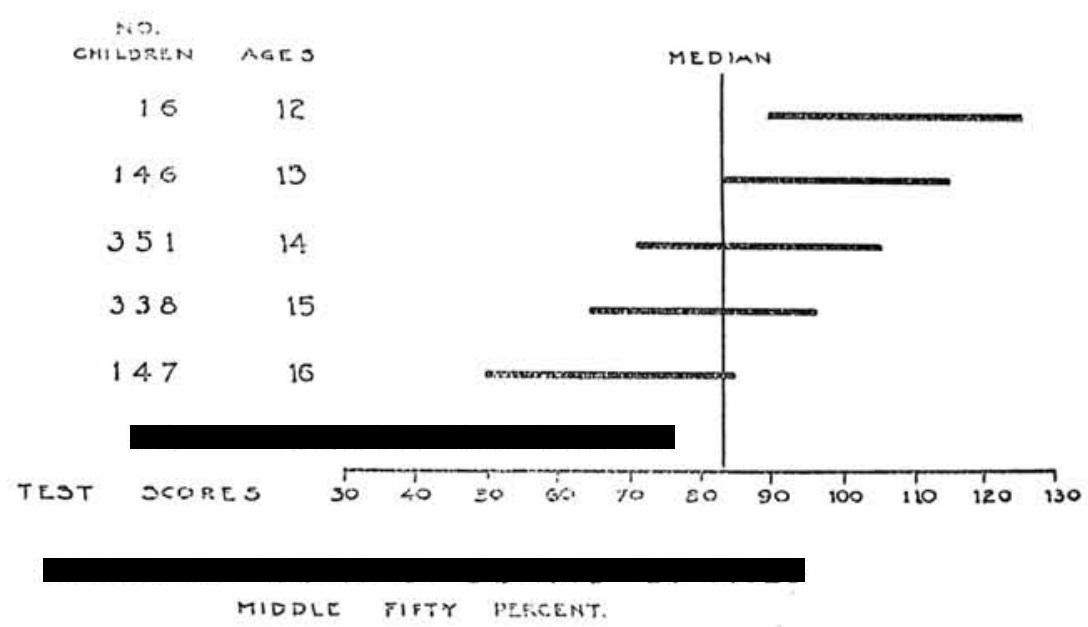

successfully in some of the Oakland schools as an aid in making pupil segregations on the basis of ability to do school work.

7. The test results are also of value in studying individual pupils. The results are not as reliable in the measurement of individuals as in the measurement of classes, but if they are used cautiously, they are sufficiently accurate to render valuable information concerning individual pupils. Following are some of the ways in which test scores may be used in dealing with individual pupils:

1. A low score may help to confirm a teacher's judgment that a child's failure in school is due to inferior capacity. Special steps can then be taken to insure the best development of what ability the child is found to possess.

2. A high score associated with poor school work should call for special study. The child may be failing because of lack of application; or such factors as excessive diffidence, poor sight, defective hearing, or bad home conditions may explain why a child sometimes makes a high score and yet does poor school work. At any rate, all such cases are worth careful investigation to see if conditions cannot be remedied so that the child will work up to capacity. Cases are already on record in the Oakland schools where the attitude of a child toward school and the character of his school work have both been greatly improved as a result of a special case study made after a group test had been given.

3. The test scores often indicate that children should be considered for extra promotions. When a child makes an exception- 
ally high score, and it is the judgment of his teachers that he is capable of doing work in a higher grade, he should be carefully studied with a view to advancement. If no good reasons seem to exist why he should not be put ahead, he should receive the extra promotion, due provision being made on account of it for the extra help he will need. On the other hand, when a child's test score and school work seem to agree, there is reason for satisfaction that the school is accomplishing what it should.

4. Test scores are valuable to teachers in educational and vocational counseling. It is only on the basis of exact knowledge that any effective advice can be given to children concerning their future educational and occupational careers. The intelligence test is one of several "lines" on a pupil's characteristics which a school counselor should have at hand when advising him.

5. The whole question of the differentiation of the curriculum in terms of the capacity and needs of pupils is one in which test results can lend valuable aid. This problem is already a pressing one in the high schools of some of our cities, for these schools are no longer receiving pupils selected almost entirely from the upper 25 percent of the general population. Indeed in some cities the freshman high-school class already has an enrollment 50 percent as large as that of the first elementary grade. Various cities report that practically all elementary-school graduates enter the high school. ${ }^{1}$ In short, our high schools are now attended by many pupils with a mental capacity that is only average or even below average. At the same time, many high schools have little to offer these children except a curriculum designed for the highly selected college-preparatory group that attended high school a few decades ago. How miserably this curriculum fails, the elimination figures of most high schools clearly show. The problem of creating a new curriculum for children of average and below-average capacity is one on which intelligence tests give valuable aid.

These are but a few of the administrative uses to which group intelligence-test data may be put. Caution is, of course, necessary. Tests have no greater enemy than the inexperienced and enthusiastic individual who rushes into a program of testing and accepts all test results at their face value.

${ }^{1}$ Of the pupils included in this study, 87 percent entered high school. 